\title{
Prevalence of oropharyngeal dysphagia in hereditary spastic paraplegias
}

\author{
Prevalência de disfagia orofaríngea nas paraparesias espásticas hereditárias \\ Lais Alves JACINTO-SCUDEIRO', Gustavo Dariva MACHADO ${ }^{5}$, Annelise AYRES ${ }^{10}$, Daniela BURGUÊZ ${ }^{5}$, Marcia \\ POLESE-BONATTO², Carelis GONZÁLEZ-SALAZAR ${ }^{9}$, Marina SIEBERT'3,7, Marcondes Cavalcante FRANCCA \\ JUNIOR ${ }^{8}$, Maira Rozenfeld OLCHIK'11, Jonas Alex Morales SAUTE ${ }^{1,4,5,6}$
}

\begin{abstract}
Hereditary spastic paraplegias (HSP) are a group of genetic diseases characterized by lower limb spasticity with or without additional neurological features. Swallowing dysfunction is poorly studied in HSP and its presence can lead to significant respiratory and nutritional complications. Objectives: The aim of this study was to evaluate the frequency and clinical characteristics of dysphagia in different types of HSP. Methods: A two-center cross-sectional prevalence study was performed. Genetically confirmed HSP patients were evaluated using the Northwestern Dysphagia Patient Check Sheet and the Functional Oral Intake Scale. In addition, self-perception of dysphagia was assessed by the Eat Assessment Tool-10 and the Swallowing Disturbance Questionnaire. Results: Thirty-six patients with spastic paraplegia type 4 (SPG4), five with SPG11, four with SPG5, four with cerebrotendinous xanthomatosis (CTX), three with SPG7, and two with SPG3A were evaluated. Mild to moderate oropharyngeal dysphagia was present in 3/5 (60\%) of SPG11 and 2/4 (50\%) of CTX patients. A single SPG4 (2\%) and a single SPG7 (33\%) patient had mild oropharyngeal dysphagia. All other evaluated patients presented with normal or functional swallowing. Conclusions: Clinically significant oropharyngeal dysphagia was only present in complicated forms of HSP. Patients with SPG11 and CTX had the highest risks for dysphagia, suggesting that surveillance of swallowing function should be part of the management of patients with these disorders.
\end{abstract}

Keywords: Spastic paraplegia, hereditary; deglutition; xanthomatosis, cerebrotendinous; deglutition disorders.

\section{RESUMO}

As paraparesias espásticas hereditárias (PEH) são um grupo de doenças genéticas caracterizado por espasticidade dos membros inferiores com ou sem características neurológicas adicionais. A disfunção da deglutição é pouco estudada nas PEH e sua presença pode levar a complicações respiratórias e nutricionais significativas. Objetivo: O objetivo deste estudo foi avaliar a frequência e a caracterização clínica da disfagia em diferentes tipos de PEH. Métodos: Foi realizado um estudo transversal em dois centros. Os pacientes com PEH confirmados geneticamente foram avaliados pelo Northwestern Dysphagia Patient Check Sheet e pela Escala Funcional de Ingestão Oral. Além disso, a autopercepção da disfagia foi avaliada pelo Eat Assessment Tool-10 e pelo Swallowing Disturbance Questionnaire. Resultados: Trinta e seis pacientes com paraplegia espástica tipo 4 (SPG4), cinco com SPG11, quatro com SPG5, quatro com xantomatose cerebrotendinosa (CTX), três com SPG7 e dois com SPG3A foram avaliados. Disfagia orofaríngea leve a moderada estava presente em 3/5 (60\%) dos pacientes com SPG11 e 2/4 (50\%) dos pacientes com CTX. Um único SPG4 (2\%) e um único SPG7 (33\%) apresentaram disfagia orofaríngea leve. Todos os outros pacientes avaliados apresentaram deglutição normal ou funcional. Conclusão: Disfagia orofaríngea clinicamente significativa estava presente apenas nas formas complicadas de PEH. A SPG11 e CTX apresentaram maiores riscos de disfagia, sugerindo que a avaliação da deglutição deve fazer parte do manejo dos pacientes com essas condições.

Palavras-chave: Paraplegia espástica hereditária; deglutição, xantomatose cerebrotendinosa; transtornos da deglutição.

\footnotetext{
'Universidade Federal do Rio Grande do Sul, Programa de Pós-Graduação em Ciências Médicas, Porto Alegre RS, Brasil;

¿2Universidade Federal do Rio Grande do Sul, Programa de Pós-Graduação em Bioquímica, Porto Alegre RS, Brasil;

${ }^{3}$ Universidade Federal do Rio Grande do Sul, Programa de Pós-Graduação em Gastroenterologia e Hepatologia, Porto Alegre RS, Brasil;

${ }^{4}$ Hospital de Clínicas de Porto Alegre, Departamento de Neurologia, Porto Alegre RS, Brasil;

${ }^{5}$ Hospital de Clínicas de Porto Alegre, Serviço de Genética Médica, Porto Alegre RS, Brasil;

${ }^{6}$ Universidade Federal do Rio Grande do Sul, Departamento de Medicina Interna, Porto Alegre RS, Brasil;

${ }^{7}$ Hospital de Clínicas de Porto Alegre, Unidade de Pesquisa Laboratorial / Centro de Pesquisa Experimental, Porto Alegre RS, Brasil;

${ }^{8}$ Universidade Estadual de Campinas, Faculdade de Ciências Médicas, Departamento de Neurologia, Campinas SP, Brasil;

'Universidade Estadual de Campinas, Programa de Pós-Graduação em Fisiopatologia Médica, Campinas SP, Brasil;

${ }^{10}$ Universidade Federal de Ciências da Saúde de Porto Alegre, Programa de Pós-Graduação em Ciências da Saúde, Porto Alegre RS, Brasil;

${ }^{11}$ Universidade Federal do Rio Grande do Sul, Faculdade de Odontologia, Departamento de Cirurgia Ortopédica, Porto Alegre RS, Brasil.

Laís Alves Jacinto-Scudeiro (iD https://orcid.org/0000-0003-2567-5322; Gustavo Dariva Machado (iD https://orcid.org/0000-0003-3388-3666; Annelise Ayres (iD) https://orcid.org/0000-0003-3205-3660; Marcia Polese-Bonatto (iD) https://orcid.org/0000-0001-6049-926X; Carelis González-Salazar (iD) https://orcid.org/0000-0003-2300-682X; Marina Siebert (iD) https://orcid.org/0000-0003-3366-2177; Marcondes Cavalcante França Junior (iD https://orcid.org/0000-0003-0898-2419; Maira Rozenfeld Olchik (iD) https://orcid.org/0000-0002-8732-9225; Jonas Alex Morales Saute https://orcid.org/0000-0003-1141-6573

Correspondence: Maira Rozenfeld Olchik; Rua Ramiro Barcelos, 2492; 90035-004 Porto Alegre RS, Brasil; E-mail: maira.olchik@ufrgs.br

Conflict of interest: There is no conflict of interest to declare.

Received 29 April 2019; Received in final form 06 August 2019; Accepted 20 August 2019.
} 
Hereditary spastic paraplegias (HSP) are a heterogeneous group of genetic diseases (> 80 loci have been described) characterized by the hallmark of progressive lower limb spasticity $^{1,2}$. Hereditary spastic paraplegias are usually classified on clinical grounds into pure forms, in which only a pyramidal syndrome is found (changes in vibratory sensation and neurogenic bladder are also accepted); and complicated forms, in which the pyramidal syndrome is accompanied by dysfunction in other neurological systems or by systemic involvement ${ }^{3}$. Spastic paraplegia type 4 (SPG4) is the most frequent autosomal dominant, and SPG11 and SPG7 are the most frequent autosomal recessive subtypes worldwide ${ }^{4,5}$.

One of the most worrisome symptoms faced by patients with neurodegenerative diseases is oropharyngeal dysphagia. Dysphagia is a swallowing disorder that modifies the process of transporting food safely and efficiently from mouth to pharynx and esophagus. Dysphagia can lead to aspiration, malnutrition, dehydration and pneumonia, all of which have a significant impact on the quality of life of patients ${ }^{6,7}$. A comprehensive description of the clinical evaluation of swallowing in the different forms of HSP is lacking in the literature, where only a few reports of dysphagia frequencies, especially in complicated HSP, were reported ${ }^{8,9}$.

Thus, the objective of this study was to verify the prevalence of swallowing disorder and to characterize the main clinical signs of dysphagia in genetically-confirmed HSP patients.

\section{METHODS}

\section{Design and subjects}

This was a two-center, exploratory, cross-sectional, prevalence study conducted at two teaching hospitals in the Brazilian cities of Porto Alegre and Campinas. The study included consecutive patients followed at the neurogenetics outpatient clinics of these hospitals, from December 2016 to August 2018, who had a genetically-confirmed diagnosis of $\mathrm{HSP}^{5}$. Other neurological or systemic conditions that could manifest dysphagia were excluded. The project was approved by the institutions' ethics committees, following the Declaration of Helsinki. Informed written consent was obtained from all individuals prior to participation.

\section{Clinical evaluation of dysphagia}

The clinical evaluation of dysphagia was performed, using the Northwestern Dysphagia Patient Check Sheet ${ }^{10}$, by a speech therapist (LAJS) trained in the protocol. The check sheet comprises a brief clinical and functional evaluation of swallowing consisting of 28 items, divided into three steps: medical history and behavioral variables, gross motor function, and an oral motor test. Liquid (100 mL of water), solid (one water cracker), and pasty (45 g yogurt cup) food were used for the functional evaluation of swallowing, which was then labeled as normal, functional swallowing, mild oropharyngeal dysphagia, mild to moderate oropharyngeal dysphagia, moderate oropharyngeal dysphagia, moderate to severe oropharyngeal dysphagia and severe oropharyngeal dysphagia, classified by the protocol of speech-language assessment of risk for dysphagia ${ }^{11}$. In addition, the functionality of oral intake was verified through the Functional Oral Intake Scale ${ }^{12}$. This scale ranges from zero to seven, with a score of zero meaning nothing by mouth, and a score of seven meaning total oral diet with no restriction.

We also applied two self-assessment instruments: the Swallowing Disturbance Questionnaire, which comprises 15 items about swallowing-related changes, where scores $\geq$ 11 indicate a risk for dysphagia ${ }^{13}$; and the Eat Assessment Tool-10, which evaluates the emotional impact and physical symptoms that swallowing problems may have on the individual's life. Its score ranges from 0 to 40, with scores $>3$ indicating a risk of oropharyngeal dysphagia ${ }^{14}$. We decided to use two different screening protocols for swallowing considering that these instruments may have differing sensitivity to identifying the risk of dysphagia in HSP patients, similar to that seen in other neurological diseases ${ }^{15}$.

\section{Neurological evaluation}

Neurological severity was assessed by the Brazilian Portuguese version of the Spastic Paraplegia Rating Scale (range: 0-52, increasing in severity) ${ }^{16}$. We also estimated the cross-sectional disease progression as the cross-sectional quotient of disease severity and disease duration, as previously established $^{2}$. Disease duration and age at onset of the first motor symptom were reported by patients and their relatives.

\section{Data analysis}

A descriptive analysis of the results obtained in the Northwestern Dysphagia Patient Check Sheet, Functional Oral Intake Scale and Eat Assessment Tool-10 was carried out in order to characterize the most prevalent findings of dysphagia for each form of HSP.

\section{RESULTS}

A total of 54 patients with HSP were enrolled in the study, including 36 SPG4 (17 families), 5 SPG11 (4 families), 4 SPG5 (1 family), 4 CTX (4 families), 3 SPG7 (3 families) and 2 SPG3A ( 1 family) patients. Table 1 shows the clinical and demographic characteristics of the patients.

Regarding the clinical evaluation of swallowing, 3/5 (60\%) and 2/4 (50\%) of SPG11 and CTX patients, respectively, presented with mild to moderate oropharyngeal dysphagia, which was the most serious clinical finding of this study. The prevalence of dysphagia in the other groups was much lower, with the majority of patients being diagnosed with normal or functional swallowing. Dysphagia prevalence and description of clinical signs for each HSP form are described in Table 2. 

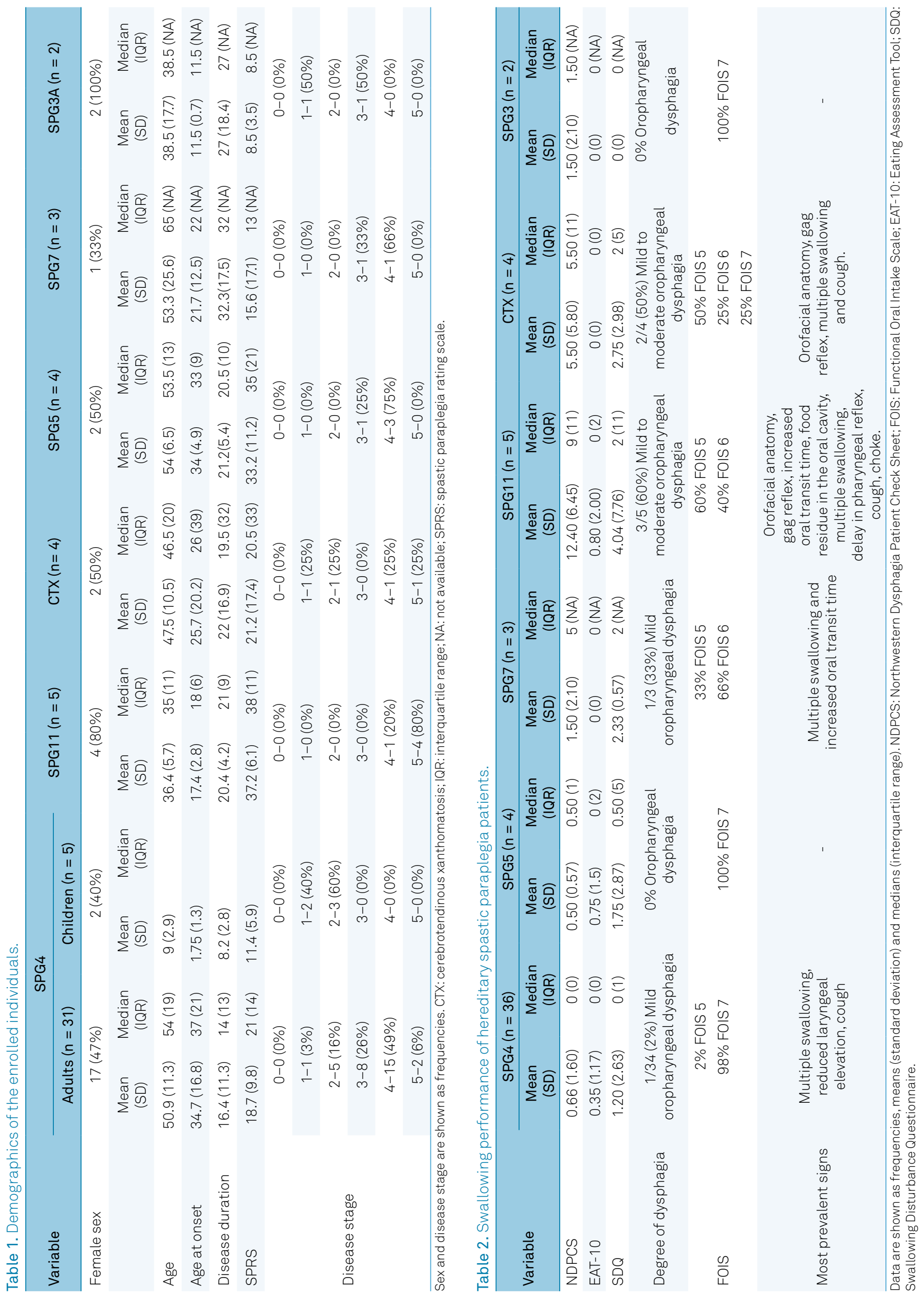
We intended to correlate swallowing performance in SPG4 with independent variables (age, disease duration and severity). However, due to the presence of dysphagia in only a single patient, this analysis was not possible.

\section{DISCUSSION}

The clinical evaluation of swallowing includes the collection of information regarding swallowing difficulties, structural and functional analysis of responsible structures, and observation of patients during swallowing attempts ${ }^{17}$. To the best of our knowledge, no previous study has focused on dysphagia characterization in HSPs.

In the present sample, $60 \%$ and $50 \%$ of patients with SPG11 and CTX, respectively, had mild to moderate oropharyngeal dysphagia, characterized by changes in the oral phase (increased oral transit time and food residue in the oral cavity for the solid consistency) and pharyngeal phase (multiple swallowing for all consistencies and cough for liquids) of swallowing. Regarding feeding functionality, all patients had a total oral diet with more than one consistency, but with the need for special preparation or compensation for most of them. Previous studies have described dysphagia prevalence from 5.7-54\% in SPG11 $1^{2,8,9}$; however, there was neither a description of the evaluation protocol nor the specific results of these alterations. In our study, most SPG11 and CTX patients (5/9) had alterations in the mobility and tonicity of phonoarticulatory organs, in addition to the reduction of the gag reflex, which may increase the risk of laryngotracheal aspiration of saliva and food in these patients. It is important to note that, although we found significant changes in the clinical evaluation protocol, the alterations were not reported by patients. Only a single individual with SPG11 reached the cut-off point indicative of risk for dysphagia in the Eat Assessment Tool-10 and Swallowing Disturbance Questionnaire; however, the validity of these tests in the context of dementia (5/5 patients with SPG11 and 2/4 with CTX met criteria for dementia in our study; data not shown) is limited and, therefore, we do not know if these patients did not have complaints related to swallowing or if they just could not reliably answer the questions.

Regarding the other evaluated HSP subtypes, we found only a single SPG4 (2\%) and a single SPG7 patient (33\%) with mild oropharyngeal dysphagia. All other patients had normal or functional swallowing with no signs of aspiration risk on the Functional Oral Intake Scale. The low prevalence of dysphagia in the pure forms of HSP that we found is even lower than the 5-5.7\% prevalence reported for SPG4 patients in previous studies based on the physician's description ${ }^{2,8}$. It should be emphasized that the single patient we have described, with SPG4 and mild dysphagia, was a 54-year-old woman with 33 years of illness who was currently wheelchair bound. This information regarding the absence of clinically perceptible changes in swallowing, even in advanced stages of pure forms of HSP, is also important for the differential diagnosis of degenerative conditions that predominantly affect the corticospinal tract, such as primary lateral sclerosis, in which dysphagia is frequent and may be an early symptom ${ }^{18}$.

A limitation of our study was the lack of an objective evaluation of swallowing, which prevented us from evaluating the presence of silent or subclinical aspirations. However, the dysphagia scales used in this study are well-validated and widely-used instruments that are easy to perform with low related $\operatorname{costs}^{10,11,12,13,14}$, giving adequate outcomes to answer the study question on the clinical characterization of oropharyngeal dysphagia in patients with HSP.

In conclusion, patients with predominantly pure forms of HSP (SPG4, SPG5 and SPG3A) have a small risk of oropharyngeal dysphagia, unlike patients with severe complicated forms such as SPG11 and CTX, where this possibility is increased, resulting in a higher risk of laryngotracheal penetration/aspiration. In this sense, the evaluation of swallowing should be performed periodically in patients with complicated forms of HSP, as part of the multidisciplinary care necessary for the adequate treatment of these patients.

\section{Acknowledgments}

The authors thank all the families who agreed to participate in our study. We also thank Prof. Dr. Leonardo Tartaruga, and Valéria Feijó Martins and Ana Paula Janner Zanardi for their support in allocating patients during the assessment phase, Prof. Dr. Ludger Schöls and Prof. Dr. Ingemar Björkhem for previous collaboration studies regarding SPG5 and 27-hydroxycholesterol analysis, and Prof. Dr. Andrea DeBarber for previous collaboration studies regarding CTX and plasma cholesterol analysis.

\section{References}

1. Depienne C, Stevanin G, Brice A, Durr A. Hereditary spastic paraplegias: an update. Curr Opin Neurol. 2007 Dec;20(6):674-80. https://doi.org/10.1097/WC0.0b013e3282f190ba

2. Schüle R, Wiethoff S, Martus P, Karle KN, Otto S, Klebe S, et al. Hereditary spastic paraplegia: clinicogenetic lessons from 608 patients. Ann Neurol. 2016 Apr;79(4):646-58. https://doi.org/10.1002/ana.24611
3. Harding AE. Classification of the hereditary ataxias and paraplegias. Lancet. 1983 May;1(8334):1151-5. https://doi.org/10.1016/S0140-6736(83)92879-9

4. Ruano L, Melo C, Silva MC, Coutinho P. The global epidemiology of hereditary ataxia and spastic paraplegia: a systematic review of prevalence studies. Neuroepidemiology. 2014;42(3):174-83. https://doi.org/10.1159/000358801 
5. Burguez D, Polese-Bonatto M, Scudeiro LA, Björkhem I, Schöls L, Jardim LB, et al. Clinical and molecular characterization of hereditary spastic paraplegias: A next-generation sequencing panel approach. J Neurol Sci. 2017 Dec;383(383):18-25. https://doi.org/10.1016/j.jns.2017.10.010

6. Logemann JA, Veis S, Colangelo L. A screening procedure for oropharyngeal dysphagia. Dysphagia. 1999;14(1):44-51. https://doi.org/10.1007/PL00009583

7. Logemann JA. Critical factors in the oral control needed for chewing and swallowing. J Texture Stud. 2014 Jun;45(3):173-9. https://doi.org/10.1111/jtxs.12053

8. Coutinho P, Barros J, Zemmouri R, Guimarães J, Alves C, Chorão $\mathrm{R}$, et al. Clinical heterogeneity of autosomal recessive spastic paraplegias: analysis of 106 patients in 46 families. Arch Neurol. 1999 Aug;56(8):943-9. https://doi.org/10.1001/archneur.56.8.943

9. Bot ST, Burggraaff RC, Herkert JC, Schelhaas HJ, Post B, Diekstra A, et al. Rapidly deteriorting course in Dutch hereditary spastic paraplegia type 11 patients. Eur J Hum Genet. 2013 Nov;21(11):1312-5. https://doi.org/10.1038/ejhg.2013.27

10. Magalhães Junior HV, Pernambuco LA, Souza LB, Ferreira MA, Lima KC. Translation and cross-cultural adaptation of the Northwestern Dysphagia Patient Check Sheet to Brazilian Portuguese. CoDAS. 2013;25(4):369-74. https://doi.org/10.1590/S2317-17822013000400012

11. Padovani AR, Moraes DP, Mangilli LD, Andrade CR. Protocolo fonoaudiológico de avaliação do risco para a disfagia (PARD). Rev Soc Bras Fonoaudiol. 2007 jul-set;12(3):199-205. https://doi.org/10.1590/S1516-80342007000300007
12. Crary MA, Mann GD, Groher ME. Initial psychometric assessment of a functional oral intake scale for dysphagia in stroke patients. Arch Phys Med Rehabil. 2005 Aug;86(8):1516-20. https://doi.org/10.1016/j.apmr.2004.11.049

13. Ayres A, Ghisi M, Rieder CR, Manor Y, Olchik MR. Rev. Translation and Cultural Adaptation of Swallowing Disturbance questionnaire for Brazilian Ppopulation. CEFAC. 2016;18(4):828-34. https://doi.org/10.1590/1982-021620161844016

14. Gonçalves MI, Remaili CB, Behlau M. Cross-cultural adaptation of the Brazilian version of the Eating Assessment Tool - EAT-10. CoDAS. 2013;25(6):601-4. https://doi.org/10.1590/S2317-17822013.05000012

15. Manor Y, Giladi N, Cohen A, Fliss DM, Cohen JT. Validation of a swallowing disturbance questionnaire for detecting dysphagia in patients with Parkinson's disease. Mov Disord. 2007 Oct;22(13):1917-21. https://doi.org/10.1002/mds.21625

16. Servelhere KR, Faber I, Coan AC, França M. Translation and validation into Brazilian Portuguese of the Spastic Paraplegia Rating Scale (SPRS). Arq Neuropsiquiatr. 2016 Jun;74(6):489-94. https://doi.org/10.1590/0004-282×20160047

17. Mathers-Schmidt BA, Kurlinski M. Dysphagia evaluation practices: inconsistencies in clinical assessment and instrumental examination decision-making. Dysphagia. 2003;18(2):114-25. https://doi.org/10.1007/s00455-002-0094-z

18. Ramanathan RS, Rana S. Demographics and clinical characteristics of primary lateral sclerosis: case series and a review of literature. Neurodegener Dis Manag. 2018 Feb;8(1):17-23. https://doi.org/10.2217/nmt-2017-0051 